\title{
A novel cell substrate candidate for rabies virus vaccine propagation and production
}

\begin{abstract}
Rabies is acute and fatal viral encephalitis and is estimated to cause more than 50000 human deaths annually. Several cell cultures have been introduced for rabies vaccine production such as human diploid (HDC), primary hamster kidney, fetal bovine kidney, chick embryo, and continuous line of monkey kidney (VERO) cells. In this study, a novel cell line, derived from dental pulp stem cells (RHDP) was used for rabies virus propagation and was compared to MRC-5 cell line. MRC-5 showed a density higher than RHDP. The total cells obtained in a $25 \mathrm{ml}$ flask, was $4.2 \times 10^{6} \pm 1.5 \times 10^{5}$ and $2.1 \times 10^{6} \pm 2.6 \times 10^{5}$ for MRC-5 and RHDP, respectively. However, RHDP reached its maximum density sooner than MRC. The maximum cell specific growth rate of RHDP was $0.034 \mu(\mathrm{h}-1)$ while that of MRC was only $0.010 \mu$ (h-1). The maximum cell division number of RHDP was 1.53 which was achieved three days after culture. Adaptation of the virus to the novel RHDP cell line was achieved after six passages of sub-culturing of the virus every 3-4 days. Rabies virus caused typical CPE and RHDP-cell-lysis in monolayers which were easily observed by microscopy. Our results suggest that RHDP could be another cell substrate candidate for rabies virus titration. The maximum specific virus production in RHDP and MRC-5 were $5.243 \mathrm{FFU} / \mathrm{cel} 1 / \mathrm{h}$ and 3.625 FFU/cell/h respectively; both had lower titers than those reported for Vero cell.
\end{abstract}

Keywords: vaccine, cell culture, rabies virus, stem cell, R. human dental pulp stem cell RHDP
Volume I Issue 3 - 2015

\author{
Mohammad Taqavian,' Mohammad Reza \\ Fazeli,' Ahmad Fayaz, ${ }^{2}$ Nasrin Samadi, ' Ashraf \\ Mohammadi, ${ }^{3}$ Hooshmand Ilka, ${ }^{4}$ Najmeh \\ Mahjoubi' \\ 'Department of Drug and Food Control, Pharmaceutical \\ Quality Assurance Research Center, Faculty of Pharmacy, Tehran \\ University of Medical Sciences, Iran \\ ${ }^{2} \mathrm{WHO}$ Collaborating Center for References and Research on \\ Rabies, Pasteur Institute, Iran \\ ${ }^{3}$ Razi Vaccine and Serum Research Institute (RVSRI), Iran \\ ${ }^{4}$ Research and Development Department, Zistdaru Danesh \\ Company, Iran
}

Correspondence: Mohammad Reza Fazeli, Department of Drug and Food Control, Pharmaceutical Quality Assurance Research Center, Faculty of Pharmacy, Tehran University of Medical Sciences, Tehran, Iran, Tel +98-9|2।484810, Fax +98-2I66959060,Email fazelimo@tums.ac.ir

Received: September 08, 2015 | Published: November 19, 2015

\section{Introduction}

Rabies is worldwide endemic fatal viral encephalitis, which continues to be a major public health and veterinary problem in many parts of the world. ${ }^{1,2}$ Rabies is an under-reported, neglected and deadly disease estimated to cause more than 50000 human deaths annually and millions of animal bites each year. ${ }^{3}$ Domestic animals, mainly dogs and cats, or wild animals (bats, monkeys, and foxes) are important virus reservoirs that transmit this disease to human and animals of great economical interest, such as cattle and horses. ${ }^{4}$

Once clinical rabies symptoms are evident, the prognosis for survival is poor and death is almost inevitable. The population at risk includes 2.5 billion people currently living in regions in which rabies is endemic. Half of the victims of dog bites and subsequently rabies and death are children younger than 15 years of age. ${ }^{5}$ Clearly, greater efforts should be made to improve the control of rabies, a zoonotic disease with the highest rate of fatality cases known to humans. One of the most important elements in the effective control of human rabies is the use of efficacious vaccines.

Since the introduction of the first vaccine by Pasteur in 1885 , many rabies vaccines were developed using various cell substrates including animal brains, avian embryos, primary mammalian cells, human diploid cell and Vero cells. Although rabies vaccine was also produced in mammalian neural tissues over 100years ago, the vaccines that were produced in cell culture and embryonated eggs have dramatically decreased human deaths throughout the world. ${ }^{6-9}$

Using neural tissue vaccine (NTV) was very common in the past and this type of crude vaccine was improved over the years, but remained associated with serious adverse events and severe neurological reactions, because of the production of antibodies against myelin or other substances of the animal nervous tissue present in the product.
Hence, the use of NTV was phased out slowly as recommended by the World Health Organization (WHO).$^{10}$

Many different cell culture systems have been used extensively in research, diagnostics and the manufacturing of biological products including vaccines. The use of cell lines allowed largescale production of vaccines using micro-carriers and cultures in bioreactors. ${ }^{11}$ Despite supporting studies reporting the safety of Vero cell as a cell substrate for vaccine production, ${ }^{12-14}$ other reports claim contamination of some cell lines including Vero cell used for vaccine production with adventitious agents. ${ }^{15}$ Therefore, a continuous search for an appropriate cell substrate for the production of vaccines remains useful.

Currently, stem cells have gained increasing attention in research because of their promising applications in medical-clinical as well as developmental biology. Stem cells have self-renewal capacity and the ability to provide differentiated and undifferentiated cells that allow a diverse range of specialized cells and tissues. They can be obtained from different tissues including the dental pulp, ${ }^{16-18}$ and the cultivation these cells under different conditions has been established. ${ }^{19-21}$ So far no report to date has documented the use of stem cells in research or for the production of rabies vaccine. In this paper we describe a novel cell substrate, stem cell line derived from dental pulp (RHDP), for the production and quality control of rabies virus vaccine. We show that rabies virus could be adapted to these cells and harvested at high titers.

\section{Material and methods \\ Cell lines}

MRC-5 cell line, passage 25 was provided by Razi Vaccine and Serum Research Institute RVSRI, Alborz, Iran. RHDP cell line derived from dental pulp stem cells, passage 174, was provided by the Razi Vaccine and Serum Research Institute RVSRI; Human Viral 
Vaccine Department, Alborz, Iran. BSR cell line was provided by the WHO collaborating center for references and research on rabies, Pasteur Institute, Tehran, Iran.

\section{Rabies virus strain}

Rabies Pasteur strain (PV) adapted to Vero cells was provided by WHO collaborating center for references and research on rabies, Pasteur Institute, Tehran, Iran.

\section{Cell culture}

MRC-5 cells were grown in Dulbecco's Modified Eagle's Medium (DMEM, Gibco BRL) supplemented with $8 \%$ fetal bovine serum (FBS, Gibco BRL) and kanamycin-neomycin (Biosera, United Kingdom) as previously described. ${ }^{22}$ Tissue culture flasks (175 or 25 $\mathrm{cm}^{2}$ ) were seeded by MRC- 5 at $1 \times 10^{5}$ cells $/ \mathrm{ml}$ and incubated at $37{ }^{\circ} \mathrm{C}$. The flasks were sub cultured when confluency was reached, normally every 6-7days. For further subculture, the cell monolayer was washed with phosphate-buffered saline (PBS) followed by $0.025 \%$ trypsin to suspend cells and subculture at appropriate concentration. The RHDP cells were cultured according to the same protocol, except that we used 5\% fetal calf serum instead of $8 \%$ and sub cultured every 4 days.

\section{Cell counting by hemocytometer}

Cell counting was performed by hemocytometer. ${ }^{22}$ Briefly, a flask containing a monolayer cell culture was trypsinized and suspended by pipetting to obtain a homogenized cell suspension. $50 \mu 1$ of cell suspension was mixed carefully with $50 \mu 1$ of $0.4 \%$ Trypan blue in a clean micro tube. A sample of stained cells was added to the counting chamber of a hemocytometer slide (Improved Neubauer, HBG, Germany). The cells were counted on a microscope and the cell concentration was calculated.

\section{Infection of cell monolayer with rabies virus:}

Virus inoculation was performed according to the modified Koprowski method. ${ }^{9}$ Briefly, the culture medium was removed and the cell monolayer was washed with PBS, then the virus seed was applied on a monolayer in a minimal volume of DMEM to cover the monolayer at a multiplicity of infection (MOI) of 0.1 and incubated at $37^{\circ} \mathrm{C}$ for $45 \mathrm{~min}$. Finally, DMEM media supplemented by $0.2 \%$ human albumin was added and incubated at $32-33^{\circ} \mathrm{C}$. The virus was harvested at different times post infection according to the experimental design.

\section{Infection of cell suspension with rabies virus}

Virus inoculation was performed according to the modified Koprowski method. ${ }^{9}$ Briefly, freshly trypsinized cells suspension were inoculated with virus seed at a MOI of 0.1 and incubated at $37^{\circ} \mathrm{C}$ for $30 \mathrm{~min}$. Then the virus propagation DMEM media supplemented by $5 \%$ FBS was added and incubation was continued at $37^{\circ} \mathrm{C}$ for 4 and 2days for MRC-5 and RHDP cell lines, respectively. After washing the cell monolayer twice with $\mathrm{PBS}$, sufficient virus propagation media was added to the flask and incubated at $32-33^{\circ} \mathrm{C}$. The virus was harvested at different times according to the experimental design.

\section{Rabies Virus titration}

Virus titer in the infected cultures was determined according to the modified Fluorescent antibody staining technique described by Kaplan ${ }^{9}$ and expressed in Fluorescent Focus Unit per ml (FFU/ $\mathrm{ml})$. Briefly, serial dilutions of virus were prepared and an aliquot of each dilution $(100 \mu \mathrm{l})$ was transferred to each chamber of a Slide Chamber (Lab Tech) followed by $200 \mu 1$ of media and $100 \mu 1$ of cell suspension. Slide chamber was incubated at $36-37^{\circ} \mathrm{C}$ for 48 hours then subjected to staining. All chambers were washed twice with PBS and after fixation of cells in acetone, the chambers were stained with anti rabies nucleocapsid conjugated antibody. Slides were examined by fluorescent microscope for presence of the Negri bodies.

\section{Cell growth kinetics}

The cell growth kinetics was calculated according to the methods used by Samia Rourou. ${ }^{23,24}$

The Specific Cell Growth rate, $\mu$ (h-1) was estimated using equation 1:

$$
\mu=\frac{\ln X_{n}-\ln X_{n-1}}{t_{n}-t_{n-1}}
$$

Where $X$ represents the viable cell density per ml, $t$ represents the time points of sampling expressed in hour, the subscripts $n$ and $n$-1 stand for two successive sampling points.

Cell Division Number, $C d$ was calculated according to the equation 2:

$$
\mathrm{Cd}=\log 2 \frac{\text { Cell density level at the end of the culture }}{\text { Cell density level at inoculation }}
$$

The virus growth kinetics was calculated according to the methods used by Samia Rourou. ${ }^{23,24}$

\section{Virus growth kinetics}

Specific Virus Production Rate, $P$ was calculated according to equation 3 :

$$
P=\frac{1}{X_{n}-X_{n+1}} \times \frac{C_{n+1}-C_{n}}{t_{n+1}-t_{n}}
$$

Where $C_{n+1}$ and $C_{n}$ represent virus titer in FFU/mL at time $t_{n}$ and $t_{n+1}$, respectively.

$X_{n}$ and $X_{n+1}$ represent cell density level at time $t_{n}$ and $t_{n+1}$, respectively.

The Overall Virus Productivity was calculated according to equation 4 :

$$
P=\frac{C}{\left(X_{\text {infection }}-X_{\text {end }}\right)} \times \frac{1}{\text { Infection period }}
$$

Where $X_{\text {infection }}$ and $X_{\text {end }}$ represent the cell density level at the time of infection and at the end of culture, respectively. $C$ stands for the virus titer in FFU/ml obtained at the end of the culture. Infection period corresponds to the duration of the virus production phase in hours.

\section{Cell infection monitoring}

Cell lines were seeded in a standard Slide Chamber and infected by $100 \mu \mathrm{l}$ of virus seed and incubated at $36^{\circ} \mathrm{C}$ for $48 \mathrm{hrs}$. The slide was then fixed with $80 \%$ cold acetone and stained with fluoresceinlabelled anti-rabies nucleocapsid antibody.

\section{Statistical evaluation}

The statistical analyses were done by Excel software. 


\section{Results}

\section{Cell growth kinetic}

To find out the kinetic of cell growth, we investigated the cell growth rate, measuring the total cell number in $25 \mathrm{~cm}^{2}$ flasks within a defined time schedule. 24 flasks were cultured by either MRC-5 or RHDP cell line according to the above mentioned methods and measured the total cell count in three flasks separately at 24-hour intervals.

The results showed that MRC-5 had a higher growth in terms of total number of cell in each flask compared with RHDP. The total cell number per $25 \mathrm{~cm}^{2}$ flask, when the monolayer was completed were $4.2 \times 10^{6} \pm 1.5 \times 10^{5}$ and $2.1 \times 10^{6} \pm 2.6 \times 10^{5}$ for MRC- 5 and RHDP, respectively (Table 1$)$.

However, the RHDP reached its maximum density sooner than MRC, as shown in Figure 1 (at day four in RHDP compared with day 8 in MRC-5).

Different parameters such as specific growth rate as well as cell division number can give us much more important information on cell behavior in culture system. So we calculated these parameters for both cell lines based on data obtained from the cell growth curve.

Specific growth rate in RHDP (which reflected the cell growth per time unit) was higher than MRC5 at all sampling time during the 8days of culture. The specific growth rate in RHDP was at its maximum level $\left(0.034 \pm 0.011 \mu^{\mathrm{h}-1}\right)$ on the first day of culture, whereas this parameter reached its maximum level $\left(0.010 \pm 0.001 \mu^{\mathrm{h}-1}\right) 3-4$ days after starting culture in MRC cell. It means that the RHDP grew more rapidly than MRC5 (Figures 2a and 2b).

Specific growth rate of MRC-5 (a) and RHDP (b) and cell division number in MRC(c) and RHDP (d). Cells were cultured in $25 \mathrm{~cm}^{2}$ flasks in static condition using DMEM supplemented by $8 \%$ and $5 \%$ FCS for MRC and RHDP cell lines, respectively.

The cell division number $(\mathrm{Cd})$ on the first day of culture for MRC and RHDP cells were $0.37 \pm 0.04$ and $0.70 \pm 0.19$, respectively. Similarly, the $\mathrm{Cd}$ on the last day of culture was $1.16 \pm 0.04$ and $1.53 \pm 0.11$ for MRC and RHDP cells, respectively. Furthermore, the $\mathrm{Cd}$ in RHDP significantly increased on day three of culture and with no significant changes for the rest of the culture period. For MRC-5, the Cd increased significantly until the sixth culture day and with no any changes then after (Table 1, Figures $2 \mathrm{c}$ and $2 \mathrm{~d}$ ).

\section{Cell infection monitoring}

The rabies virus (PV strain) underwent passage on monolayers of RHDP cell line in $25 \mathrm{~cm}^{2}$ tissue culture flask. One slide chamber was prepared in parallel at each passage and stained for microscopic investigation. The slide chambers were stained with fluoresceinlabelled antirabies nucleocapsid antibody.

In the first virus passage on the cell substrate, limited focuses were seen but the number of these focuses increased in subsequent passages and massive focuses were observed in the sixth passage (Figure 3).

\section{Virus growth kinetic}

To study the effect of the cell substrate on virus productivity, a sufficient number of cell culture flasks were provided and inoculated with virus seed according to the monolayer method. Samples were withdrawn at 24-hour intervals and cell concentrations as well as virus titer were measured in the samples. The specific virus production rate and the virus productivity were calculated using data obtained from the above mentioned methods (Table 2).

Table I Cell growth parameters for MRC-5 and RHDP cell lines cultured in flas

\begin{tabular}{lllllll}
\hline $\begin{array}{l}\text { Time After Starting } \\
\text { Culture Hr }\end{array}$ & \multicolumn{2}{l}{$\begin{array}{l}\text { Total Cell Count Per 25 Cm2 Flask } \\
\text { Mean } \pm \text { SD }\end{array}$} & $\begin{array}{l}\text { Specific Growth Rate M (H-I) } \\
\text { Mean } \pm \text { SD }\end{array}$ & $\begin{array}{l}\text { Cell Division Number(Cd) } \\
\text { Mean } \pm \text { SD }\end{array}$ \\
\hline & MRC-5 & RHDP & MRC-5 & RHDP & MRC-5 & RHDP \\
24 & $1.3 * 106 \pm 1.5 * 105$ & $9.3^{*} 105 \pm 2.5 * 105$ & $0.008 \pm 0.005$ & $0.034 \pm 0.011$ & $0.37 \pm 0.04$ & $0.70 \pm 0.19$ \\
48 & $1.7 * 106 \pm 1.5 * 105$ & $1.3^{*} 106 \pm 3.1 * 105$ & $0.008 \pm 0.002$ & $0.024 \pm 0.005$ & $0.46 \pm 0.04$ & $1.00 \pm 0.23$ \\
72 & $2.3 * 106 \pm 2.0 * 105$ & $2.03 * 106 \pm 2.5 * 105$ & $0.010 \pm 0.001$ & $0.023 \pm 0.002$ & $0.63 \pm 0.05$ & $1.53 \pm 0.19$ \\
96 & $2.9 * 106 \pm 2.1 * 105$ & $2.03 * 106 \pm 1.1 * 105$ & $0.010 \pm 0.001$ & $0.017 \pm 0.001$ & $0.78 \pm 0.06$ & $1.53 \pm 0.19$ \\
120 & $3.5 * 106 \pm 3.0 * 105$ & $2.1 * 106 \pm 2.0 * 105$ & $0.009 \pm 0.001$ & $0.014 \pm 0.001$ & $0.96 \pm 0.08$ & $1.58 \pm 0.15$ \\
144 & $4.1 * 106 \pm 3.5 * 105$ & $2.1 * 106 \pm 2.6 * 105$ & $0.009 \pm 0.001$ & $0.012 \pm 0.001$ & $1.13 \pm 0.10$ & $1.58 \pm 0.20$ \\
168 & $4.2 * 106 \pm 2.6 * 105$ & $1.9 * 106 \pm 1.5 * 105$ & $0.008 \pm 0.0004$ & $0.009 \pm 0.0004$ & $1.15 \pm 0.07$ & $1.48 \pm 0.11$ \\
\hline
\end{tabular}

Table 2 Virus production parameters in MRC-5 and RHDP cell substrate in static culture flask

\begin{tabular}{|c|c|c|c|c|c|c|}
\hline \multirow[t]{2}{*}{$\begin{array}{l}\text { Time After Virus } \\
\text { Inoculation Hrs }\end{array}$} & \multicolumn{2}{|c|}{ Total Cell Count Per/MI Mean \pm SD } & \multicolumn{2}{|c|}{$\begin{array}{l}\text { Specific Virus Production } \\
\text { Rate FFU/Cell/H }\end{array}$} & \multicolumn{2}{|c|}{ Virus Productivity Mean \pm SD } \\
\hline & MRC-5 & RHDP & MRC-5 & RHDP & MRC-5 & RHDP \\
\hline 24 & $4.0 * 105 \pm 1.0 * 104$ & $1.8 * 105 \pm 2.1 * 104$ & 0.0028 & 0.0092 & $0.0479 \pm 0.027$ & $0.0599 \pm 0.064$ \\
\hline 48 & $4.1 * 105 \pm 2.5 * 104$ & $1.9 * 105 \pm 0.6 * 104$ & 0.0292 & 0.1056 & $0.0372 \pm 0.023$ & $0.1326 \pm 0.038$ \\
\hline 72 & $4.15 * 105 \pm 2.7 * 104$ & $1.8 * 105 \pm 1.7 * 104$ & 1.375 & 1.4072 & $0.2199 \pm 0.083$ & $0.9769 \pm 0.563$ \\
\hline 96 & $4.3 * 105 \pm 2.0 * 104$ & $1.6 * 105 \pm 1.0 * 104$ & 1.6024 & 5.2431 & $3.4826 \pm 2.920$ & $2.4682 \pm 0.035$ \\
\hline 120 & $4.26 * 105 \pm 1.5 * 104$ & $1.13 * 105 \pm 1.5 * 104$ & 3.625 & 0.0774 & $2.46 \mathrm{II} \pm 2.234$ & $\mathrm{I} .0335 \pm 0.48 \mathrm{I}$ \\
\hline 144 & $4.3 * 105 \pm 2.1 * 104$ & $0.47 * 105 \pm 1.5 * 104$ & 0.0417 & 0.5625 & $2.3248 \pm 3.521$ & $0.2465 \pm 0.170$ \\
\hline
\end{tabular}

MRC-5 cell densities were $4.0^{*} 10^{5} \pm 1.0 * 10^{4}$ and $4.3 * 10^{5} \pm$ $2.1 * 10^{4}$ per $\mathrm{ml}$ at 24 and 144 hours after initiating the virus inoculation, respectively. An almost constant cell concentration was seen and no significant changes in cell density were observed during the 6 days of cell infection $(\mathrm{P}>0.05)$ (Figure $4 \mathrm{a})$. However, a constant increase in virus titer was noted during the incubation period. The highest virus titer was reached on the sixth day. The specific virus production rate was $0.0028 \mathrm{FFU} / \mathrm{cell} / \mathrm{h}$ and $3.625 \mathrm{FFU} / \mathrm{cell} / \mathrm{h}$ on day one and five, respectively (Table 2 and Figure $4 b$ ).

In contrast, the RHDP cell densities were $1.8 * 10^{5} \pm 2.1 * 10^{4}$ and $0.47 * 10^{5} \pm 1.5^{*} 10^{4}$ per $\mathrm{ml}, 24$ and 144 hours after initiating the virus 
inoculation, respectively (Table 2). We found a significant decrease in cell density during the six days of virus propagation, starting from day $4(\mathrm{P}<0.05)$. At the end of the infection phase, almost all cells had experienced lysis or were rounded and detached, because of the cytopathy effect (CPE) of rabies virus on RHDP cell substrate.

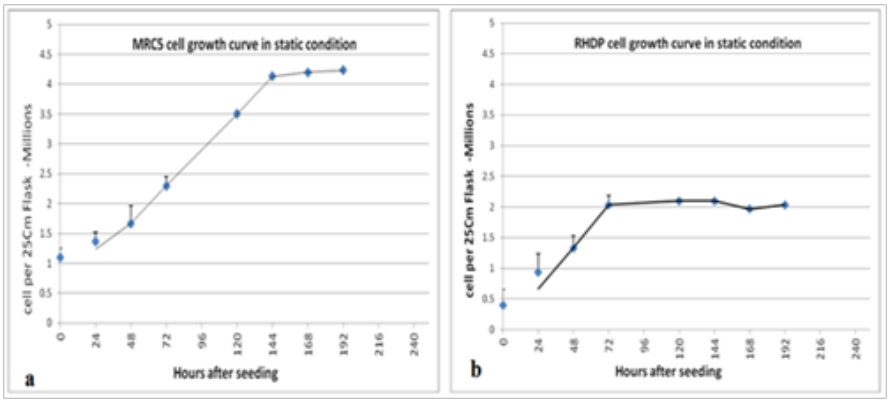

Figure I Cell growth curve of MRC-5 (a) and RHDP (b). Cells were cultured in $25 \mathrm{~cm}^{2}$ flasks in static condition, using DMEM supplemented by $8 \%$ and $5 \%$ FCS for MRC and RHDP cell lines, respectively.

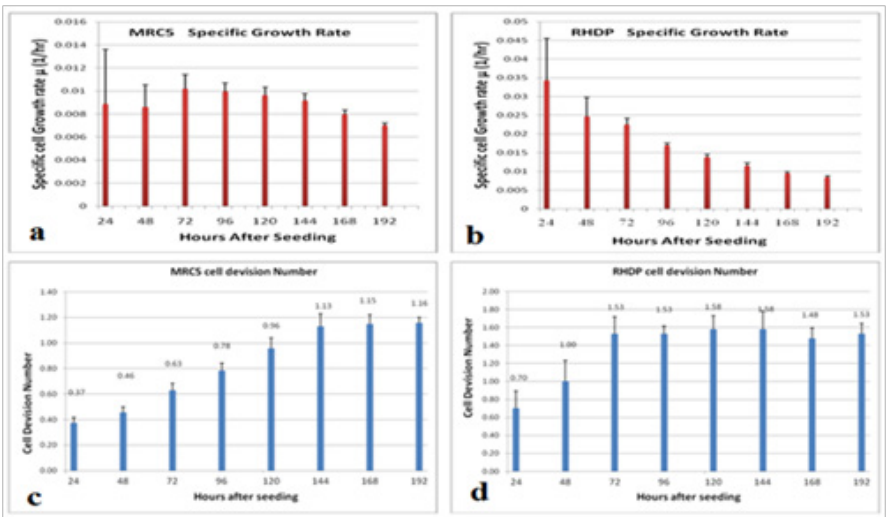

Figure 2 Most important growth parameters in cell culture system.
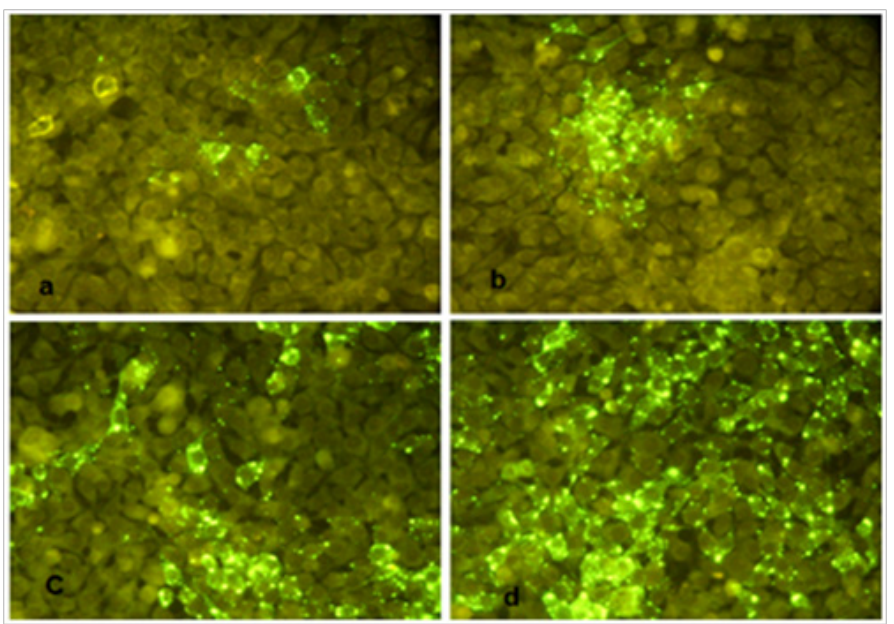

Figure 3 Photomicrographs of rabies inclusion Negri bodies in RHDP cell substrates infected by PV rabies virus strain. First (a), second (b), forth (c) and sixth (d) passages of virus on RHDP cell line. Sharpe increasing in number of fluorescence focuses in subsequent passages is noted.The slides were stained with fluorescein-labelled antirabies nucleocapsid antibody.

After cell infection, a sharp decrease of cell density with a concomitant secretion of the virus into the culture medium was observed in the RHDP cell line. The maximum virus titer was reached 4 days post infection. The specific virus production rates were 0.0092 $\mathrm{FFU} / \mathrm{cell} / \mathrm{h}$ and $5.2431 \mathrm{FFU} / \mathrm{cell} / \mathrm{h}$ on day one and four, respectively (Table 2 and Figure 4c, 4d).
The Mean virus productivities were $0.0372 \pm 0.0231$ and $0.1326 \pm 0.0375$ for MRC and RHDP cell respectively, $48 \mathrm{hrs}$ after inoculation. This parameter reached its maximum level on the fourth day of culture then decreased dramatically in both cell substrate as shown in figures $4 \mathrm{~b}$ and $4 \mathrm{~d}$. The maximum level of virus productivity was $3.4826 \pm 2.9216$ and $2.4682 \pm 0.0351$ for MRC and RHDP cells, respectively (Table 2).

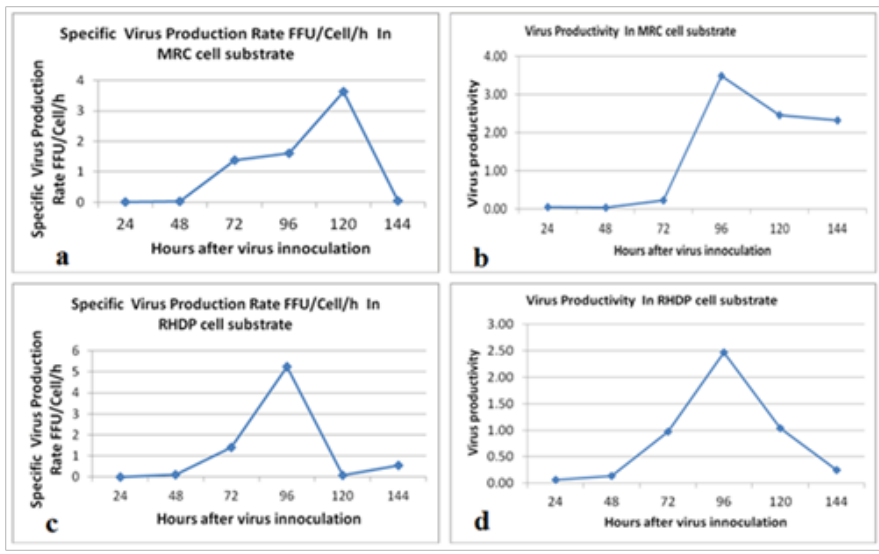

Figure 4 The kinetic of rabies virus production in MRC- 5 and RHDP cell substrates under static condition. DMEM supplemented by $0.2 \%$ human albumin was used as virus propagation media. The Specific Virus Production Rate in MRC (a) and RHDP (c) are depicted. The virus productivity is shown for MRC (b) and RHDP (d).

\section{Discussion}

Vaccination as a deliberate attempt to protect humans against infectious diseases has a long history; although only in the 20th century did the practice flourish into the routine vaccination of large population. Rabies is an acute viral-encephalitis that is transmitted from animal to animal or from animal to human by exposure to saliva. All mammalian species are believed to be susceptible to rabies. In an area in which animal control programs are not extensively developed, dogs and cats account for most of the reported rabid animals and cause most (90\%) of the human rabies exposures. Wildlife is the main reservoir of the rabies virus. ${ }^{25,26}$ Human infection with the virus occurs often after a bite from a rabid animal. However, exposure through the inhalation of the virus or through the transplantation of infected corneas have also occurred. ${ }^{27}$

One of the most important elements to effectively control human rabies is using an efficacious vaccine. Intensive efforts were exerted, world-wide, to produce cost-effective vaccines that meet or improve the levels of safety and efficacy achieved with human diploid cells. ${ }^{6,25,28}$

Animal cell culture was established as a manufacturing technology for the preparation of viral vaccines since the late 1940s. ${ }^{23}$ However, the use of cell substrate presents several disadvantages such as the potential to induce hypersensitivity, batch variability, and possibility of contaminants with adventitious agents, heterogenic proteins, bovine viruses, prions, mycoplasma, DNA, and other components. Therefore, the requirements for the use of animal cells as in vitro substrates for the production of biologicals were published by the WHO. ${ }^{29}$

However, there are some safety issues using cell lines including Vero cell. ${ }^{15}$ Moreover, because of absence of rabies CPE on cell substrate, different techniques such as titration in mice and staining with fluorescence conjugated rabies virus-nucleocapsid-antibodies are applied for virus titration. Some of these methods are expensive and/or time consuming. 
In this study, we investigated the characteristic of the RHDP cell line (a cell line derived from human dental pulp stem cell) in terms of growth in stationary condition and use as a substrate for the propagation of rabies virus, compared with MRC-5 cell substrate. Also we evaluated the potential application of this cell line for vaccine production as well as using it in developmental research.

Both MRC-5 and RHDP cell lines were evaluate according to their growth parameters as well as virus propagation characteristics. We found that MRC-5 had a higher growth rate in terms of total cell number in each flask compared with RHDP. The total cells per a $25 \mathrm{~cm}^{2}$ flask with a confluent monolayer, were $4.2 * 106 \pm 1.5 * 105$ and $2.1 * 106 \pm 2.6 * 105$ for MRC-5 and RHDP, respectively, but the RHDP reached its maximum density sooner than MRC-5.

The specific growth rates were $0.034 \pm 0.011 \mu$ (h-1) and $0.010 \pm 0.001 \mu$ (h-1) in RHDP and MRC-5, respectively. Maximum specific growth rate in RHDP was on day one of subculture and therefore, the lag time was very short. Meanwhile, the maximum growth rate in MRC-5 was observed on days 3 and 4 of culture, showing a relatively long lag phase. It can be concluded that RHDP grows more rapidly than MRC-5. However, the specific growth rate in RHDP was higher than those reported in other studies on Vero cell. ${ }^{23}$

The Cd plot was also consistent with these findings. Cd was $0.7 \pm 0.19$ on day one after starting the culture and reached $1.53 \pm 0.19$ on day 3 and fixed at this level. Therefore, for expanding the RHDP cell in an optimum condition, sub culture should be made every 3-4days to obtain the maximum cell in a defined period of time.

RHDP is highly sensitive to rabies virus and as shown in figure 3 , the virus was well adapted to this cell substrate in only 6 passages. Rabies virus can cause cell lysis and develop a CPE in RHDP cell monolayer which can be easily observed by light inverted microscope. The CPE is characterized by cells granulation and rounding, cell lysis and finally cell detachment.

This ability can make the RHDP as a cell substrate which can potentially be used for virus titration.

Recent evidence suggest that the dental pulp stem cells are thought to be mesenchymal stem cells, and able to differentiate into a wide variety of other cell and tissue types including neural cells, adipocytes, osteoblasts, chondrocytes. ${ }^{30}$ Therefore, special attention should be for using RHDP as a cell substrate for vaccine production.

A significant decrease in cell density after virus inoculation was observed in RHDP cell line and it was due to cell lysis which is concomitant with virus release in media. The RHDP cell densities 24 and 144 hours after initiating the virus inoculation were $1.8 * 105 \pm 2.1 * 104$ and $0.47 * 105 \pm 1.5 * 104$ per $\mathrm{ml}$, respectively. No significant changes in cell density were observed during the virus propagation on MRC-5 cell substrate. Only a slight change included limited and small granule in some cells or cell inflation in some cases at sixth inoculation day were observed.

The maximum specific virus production rate in RHDP was higher than MRC-5 and was $5.243 \mathrm{FFU} / \mathrm{cell} / \mathrm{h}$ for RHDP compared with 3.625 FFU/cell/h for MRC-5 and in both cases was less than those reported for Vero cell cultured in suspension condition. ${ }^{23}$

Maximum virus productivities were $3.4826 \pm 2.9216$ and $2.4682 \pm 0.0351$ for MRC-5 and RHDP cells, respectively, both observed on day four. Cell lysis in RHDP had caused such decrease in virus productivity compared with MRC cell line. The ability to amplify and support a virus replication in a cell substrate is a valuable indicator for evaluating the cell, to select it as a suitable substrate for vaccine production or further study. Virus Productivity can reflect this ability in cell substrate which can easily be calculated base on cell and virus growth kinetics. Higher Virus Productivity means more virus particle produced by a single cell.

Using micro carrier for mass production of Vero cell as well as stem cell by fermentor has been reviewed by many researchers and well documented ${ }^{19-21}$ and can be used for RHDP cultivation in large scales to increase the virus titer.

In conclusion, in this study a new cell substrate (RHDP) was presented which can be used for propagation of rabies virus and vaccine researches. All essential elements such us cell kinetic as well as virus growth properties on both, RHDP and MRC- 5 cell substrates were investigated. To the best of our knowledge, this is the first report on a stem cell derived cell line (RHDP), used for rabies virus propagation. Nevertheless, further studies are still needed to improve the culture conditions and increase production using a bioreactor. Also more studies are essential to introduce a rabies virus titration method base on RHDP cell culture.

\section{Acknowledgements}

We would like to thank the Research Department of the Tehran University of Medical Sciences for financing the current work. We also thank the Human Viral Vaccine Department, Razi Vaccine \& Serum Research Institute and WHO collaborating center for references and research on rabies, Pasteur Institute, Tehran, Iran for their support.

\section{Conflicts of interest}

Author declares there are no conflicts of interest.

\section{Funding}

None.

\section{References}

1. World Health Organization (WHO). Rabies and envenomings: a neglected public health issue: report of a Consultative Meeting, World Health Organization, Geneva. 2007.

2. Sampath G, Madhusudana SN, Sudarshan MK, et al. Immunogenicity and safety study of Indirab: A Vero cell based chromatographically purified human rabies vaccine. Vaccine. 2010;28(24):4086-4090.

3. World Health Organization (WHO). World survey of rabies No. 35 for the year 1999, World Health Organization, Geneva. 1999.

4. Frazatti-Gallina NM, Mourão-Fuches RM, Paoli RL, et al. Verocell rabies vaccine produced using serum-free medium. Vaccine. 2004;23(4):511-517.

5. Rupprecht CE, Hanlon CA, Hemachudha T. Rabies re-examined. The Lancet Infect Dis. 2002;2:327-343.

6. Recommendations for inactivated rabies vaccine for human use produced in cell substrates and embryonated eggs. WHO Expert Committee on Biological Standardization. World Health Organization Geneva. Annex 2 (WHO Technical Report Series, No. 2007.941).

7. Wiktor TJ, Plotkin SA, Koprowski H. Development and clinical trials of the new human rabies vaccine of tissue culture (human diploid cell) origin. Dev Biol Stand. 1978; 40:3-9.

8. Burgoyne GH, Kajiya KD, Brown DW, et al. Rhesus diploid rabies vaccine (adsorbed): a new rabies vaccine using FRhL-2 cells. $J$ Infect Dis. 1985;152(1):204-210. 
9. Martin MK, Hilary K. Laboratory techniques in rabies. (3rd edn), Geneva:World Health Organization. 1973.

10. Prem Kumar A, Mani KR, Palaniappan C, et al. Purification, potency and immunogenicity analysis of Vero cell culture-derived rabies vaccine: a comparative study of single-step column chromatography and zonal centrifuge purification. Microbes Infect. 2005;7(9-10):1110-1116.

11. Mendonça RZ, Ioshimoto LM, Mendonça RM, et al. Preparation of human rabies vaccine in VERO cell cultures using a microcarrier system. Bra J Med Biol Res . 1993;26(12):1305-1317.

12. Furesz J, Fanok A, Contreras G, et al. Tumorigenicity testing of various cell line substrates for production of biologicals. Dev Biol Stand. 1989;70:233-243.

13. Vincent-Falquet JC, Peyron L, Souvras M, et al. Qualification of working cell banks for the Vero cell line to produce licensed human vaccines. Dev Biol Stand. 1989;70:153-156.

14. Horaud F. Absence of viral sequences in the WHO-Vero cell bank: a collaborative study. Dev Biol Stand. 1992;76:43-46.

15. Victoria JG, Wang C, Jones MS, et al. Viral Nucleic Acids in LiveAttenuated Vaccines: Detection of Minority Variants and an Adventitious Virus. J Virol. 2010;84(12):6033-6040.

16. Huang AH, Chen YK, Lin LM, et al. Isolation and characterization of dental pulp stem cells from a supernumerary tooth. J Oral Pathol Med. 2008;37(9):571-574.

17. Agha-Hosseini F, Jahani MA, Jahani M, et al. In vitro isolation of stem cells derived from human dental pulp. Clin Transplant. 2010;24: E23E28.

18. Sloan AJ, Waddington RJ. Dental pulp stem cells: what, where, how? Int J Paediatr Dent. 2009;19(1):61-70.

19. Deborah S. Growth and Metabolism of Mesenchymal Stem Cells Cultivated on Microcarriers. PhD thesis. volgens besluit van het College voor Promoties in het openbaar te verdedigen netherlands, ISBN. 2010;1978-90-365-3018-7.
20. Phillips BW, Horne R, Lay TS, et al. Attachment and growth of human embryonic stem cells on microcarriers. Journal Biotechnol. 2008;138(1-2):24-32.

21. Oh SK, Chen AK, Mok Y, et al. Long-term microcarrier suspension cultures of human embryonic stem cells. Stem Cell Res. 2009;2:219-230.

22. Ian Freshney R. Culture of animal cells. A manual of basic technique and specialized applications. (6th edn), Wiley-Blackwell. 2010.

23. Rourou S, van der Ark A, van der Velden T, et al. A microcarrier cell culture process for propagating rabies virus in Vero cells grown in a stirred bioreactor under fully animal component free conditions. Vaccine. 2007;25(19):3879-3889.

24. Trabelsi K, Rourou S, Loukil H, et al. Optimization of virus yield as a strategy to improve rabies vaccine production by Vero cells in a bioreactor. Journal Biotechnol. 2006; 121(2):261-271.

25. Stanly AP, walter A O, Paul AO. Vaccines. (4th edn), Esevier Inc. 2004

26. David M K, Peter M H. Fields Virolog. (4th edn), LippincottRaven,Philadelphia, USA. 2001.

27. Mohammad Ali Javadi, Ahmad Fayaz, Seyed Ali Mirdehghan, et al Transmision of Rabies by Corneal Graft. Cornea. 1996;15(4):431-433.

28. Mahmoud Bahmanyar, Ahmad Fayaz, Shokrollah Nour-Salehi, et al. Successful protection of humans exposed to rabies infection. Post exposure treatment with the new human diploid cell rabies vaccine and antirabies serum.Wilderness \& Environmental Medicine. 2010;11(1):42-46.

29. Requirements for the use of animal cells as in vitro substrates for the production of biologicals. WHO Expert Committee on Biological Standardization. Forty-seventh report. Geneva, World Health Organization. WHO Technical Report Series, No. 878. Annex 1. 1998.

30. Stevens A, Zuliani T, Olejnik C, et al. Human dental pulp stem cells differentiate into neural crest-derived melanocytes and have label-retaining and sphere-forming abilities. Stem Cells and Dev. 2008;17(6):1175-1184. 